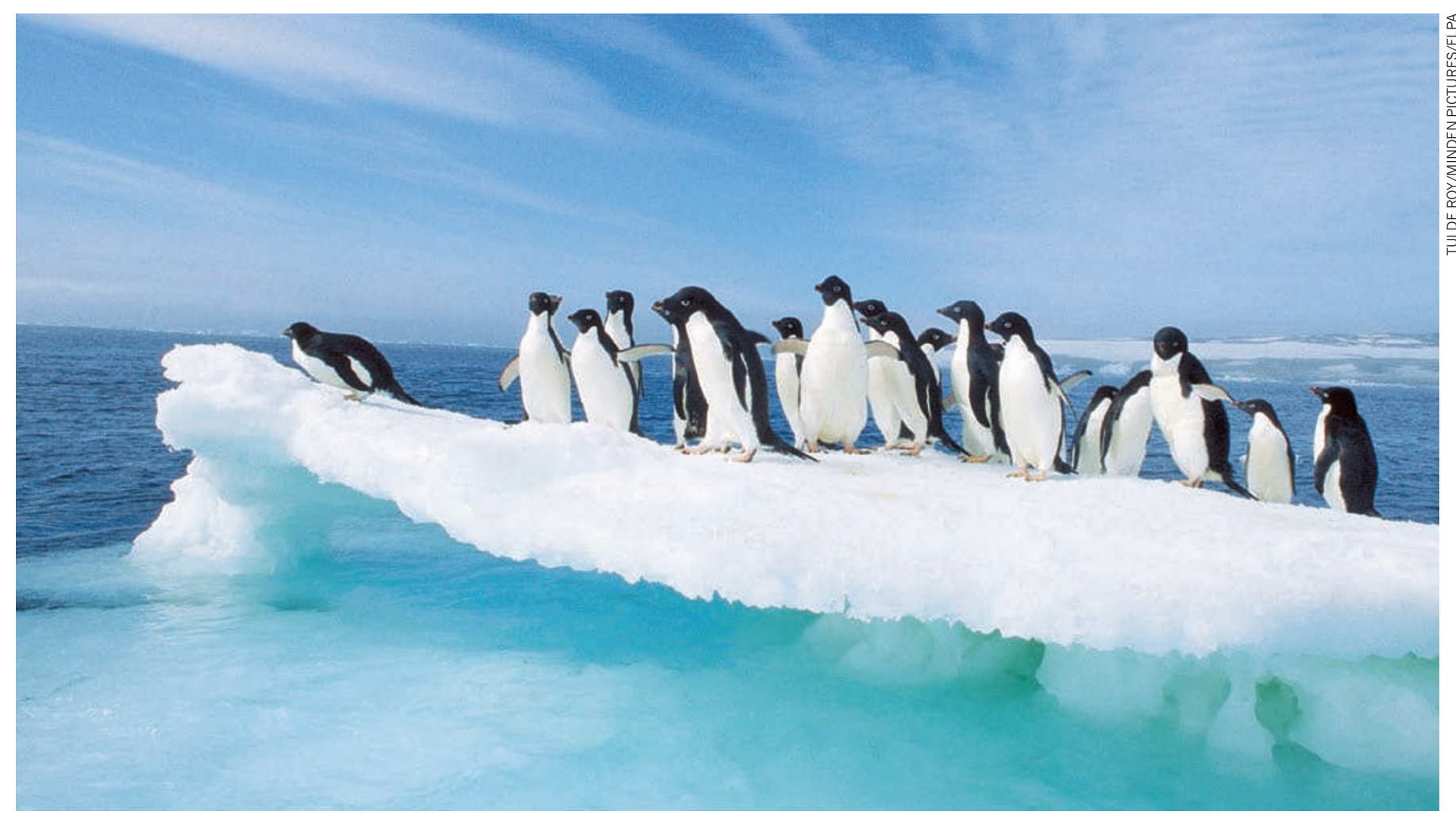

The future of the Adélie penguin hangs in the balance as sea-ice loss in the Antarctic threatens the supply of staple prey such as krill.

CONSERVATION

\title{
After the ice
}

\section{Yvon Le Maho is moved by a powerful account of the demise of the Adélie penguin.}

\section{$\mathrm{T}$} he impact of human activities on biodiversity is slow and insidious. Documenting the dramatic drop in populations of the Adélie penguin that has accompanied sea-ice loss and glacier retreat over the past three decades in the Antarctic, Fraser's Penguins reveals the profound environmental changes that are afoot.

Award-winning journalist Fen Montaigne spent five months in Antarctica tracking penguins with ecologist Bill Fraser and his team. Fraser, a regular visitor to the US scientific station of Palmer in the northwest Antarctic peninsula since 1974, has witnessed the site change from a polar ice habitat into a milder sub-Antarctic environment. Resisting the temptations of a quick research payoff, he began some of the first long-term studies on Antarctic seabird species, including the Adélie penguin (Pygoscelis adeliae). Such extended monitoring is an essential tool for assessing the health of regional ecosystems.

As a researcher who visits Antarctica regularly, I found Montaigne's account exceptionally poignant. He voices the emotions that inundate everyone who works in this vast wilderness. And he captures details such as the fantastic scenery as the boat picks its way through broken sea ice dotted with resting seals and groups of penguins squint-eyed under a dazzling light. This was especially touching because I read the book while rolling at sea in the company of wandering albatrosses, on the way to my own

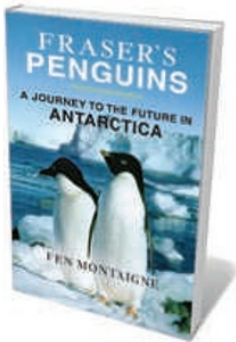

Fraser's Penguins: A Journey to the Future in Antarctica FEN MONTAIGNE Henry Holt: 2010. 288 pp. $\$ 26$ penguin study site.

Montaigne reminds us why the Adélie penguins, those "smart and fussy little men in evening clothes", fascinated the first Antarctic explorers such as Fabian von Bellingshausen, Ernest Shackleton, Roald Amundsen, Robert Scott and Edward Wilson. Those men had to fight against the cold to conquer the unforgiving Terra Australis Incognita, or 'unknown southern land'. Yet the diminutive Adélie penguins thrive in these harsh conditions thanks to a unique suite of adaptations.

Penguins have evolved layers of overlapping scale-like feathers and large reserves of energy-giving body fat, which allow them to swim through the icy waters and stand through fierce storms. After heavy snow falls on their breeding colonies, their heads may be barely visible, sticking out of breathing holes as they continue incubating their eggs.

Visitors a century ago would probably have seen huge colonies of Adélie penguins. At the start of Fraser's study, in the 1970s, there were more than 30,000 breeding pairs on the seven monitored islands around Palmer station. Populations there today have dropped by $80 \%$. Shifting weather and snow patterns, the contraction of sea ice and the retreat of glaciers have impacted ecosystems through a cascade of effects along the food web. The Adélie penguins' existence is intertwined with the presence of sea ice, as they forage on ice-dependent

\section{DNATURE.COM} Hybridization of Arctic species: go.nature.com/zhkhul 
prey such as silverfish and krill.

Sea ice serves as a grazing area for juvenile krill, who rake free the life-sustaining diatoms and phytoplankton embedded in the frozen ocean. As sea ice has declined along the western Antarctic peninsula, krill populations have dropped by up to $80 \%$ since 1976. Fisheries exacerbate the scarcity, as demand for krill in the aquaculture and pharmaceutical industries increases.

Montaigne gives an accurate portrayal of the breeding cycle and habits of the Adélie penguin. With their late maturity, low fecundity and extended generations, long-lived organisms such as penguins (and Arctic polar bears) are particularly sensitive and thus vulnerable to rapid environmental changes and extreme events. For example, my colleagues and I have shown that an increase of only $0.3^{\circ} \mathrm{C}$ in sea-surface temperature in the marginal sea-ice zone leads to a $10 \%$ drop in the survival rate of king penguins.

In revealing the tragic fate of the Adélie penguin, Montaigne has found an effective way to communicate the impact of human-induced global climate change. $\mathrm{He}$ ably explains complex climate mechanisms, such as how shifts in atmospheric circulation patterns like the Arctic Oscillation can pump warmer air into the polar regions from lower latitudes, and why some parts of the Antarctic are becoming colder when most of the peninsula's glaciers are in retreat and massive ice shelves are collapsing.

Fraser forecasts that, in the next decade, the Adélie penguins around Palmer will become memories. Rising temperatures around the Antarctic are pushing specialized polar species such as the Adélie to regional extinction. Two sub-Antarctic penguin species, gentoos and chinstraps, seem to be benefiting from climate change by expanding south. Yet they too depend on krill and winter sea ice. Although these two species might be able to shift their diet to other prey - gentoos dive deeper than the Adélie and chinstraps can feed at night - the ongoing ecosystem upheaval will jeopardize all penguins' existence in the near future.

Having worked in a more southerly part of Antarctica not yet so transformed by global warming, I found the book a piercing cry of alarm. I realize that I am lucky to have had the chance to contemplate the ecology of a pristine polar environment. As Fraser's Penguins shows, the beginning of the catastrophic consequences of global warming are only just visible now. The next generation of scientists may witness these changes accelerating at a dramatic pace.

Yvon Le Maho is CNRS research director at the Department of Ecology, Physiology and Ethology, Institut Pluridisciplinaire Hubert Curien, University of Strasbourg, France. e-mail:yvon.lemaho@iphc.cnrs.fr

\section{Books in brief}

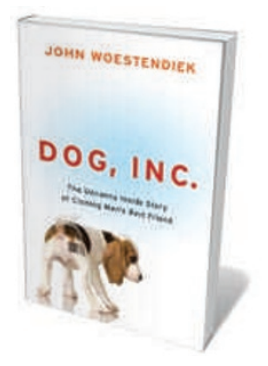

Dog, Inc.: The Uncanny Inside Story of Cloning Man's Best Friend John Woestendiek AVERY 320 pp. \$26 (2010)

Pet cloning is big business. Investigative reporter John Woestendiek looks behind the scenes at the emerging industry of commercial dog cloning. It started in 2008 with a pitbull called Booger, whose American owner loved him so much she paid US\$50,000 to a South Korean firm to produce a litter of his identical offspring. Woestendiek suggests that the ethics of dog cloning is driven as much by our love of man's best friend as by the underlying science. He asks whether our obsession with animals makes us more likely to transgress ethical boundaries.

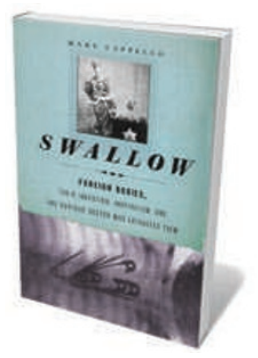

Swallow: Foreign Bodies, Their Ingestion, Inspiration, and the Curious Doctor Who Extracted Them

Mary Cappello THE NEW PRESS 336 pp. \$27.95 (2010)

Coins, jewellery, a padlock, a toy goat — people ingest the strangest things. Focusing on items rescued from patients' stomachs, awardwinning writer Mary Cappello explores the psychology of why people eat non-nutritional objects. Her book centres on physician Chevalier Jackson's collection of swallowed artefacts in Philadelphia's Mütter Museum. Through the tales behind that exhibit, she unearths a history of class and poverty that compelled boys to swallow their last coins, and explores colourful characters such as sword swallowers.

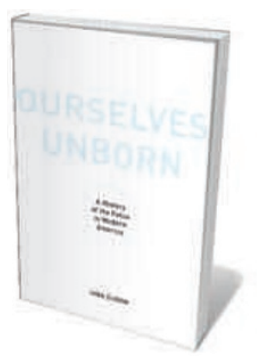

Ourselves Unborn: A History of the Fetus in Modern America Sara Dubow OXFORD UNIVERSITY PRESS 320 pp. \$29.95 (2010) We attach to the fetus a host of meanings - political, cultural and scientific. Historian Sara Dubow argues that these are largely based on our notions of identity, authority and sexuality, rather than fact or theology. She examines how these meanings have changed throughout history. Since the late nineteenth century, the fetus has been at the centre of a tug of war between science and religion. Although technology brought a greater understanding of embryo development in the twentieth century, social change has also made the fetus the subject of controversy.

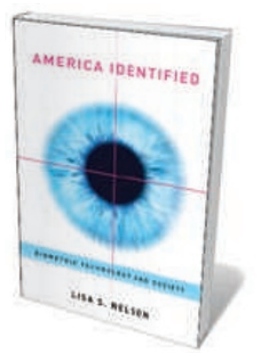

America Identified: Biometric Technology and Society

Lisa S. Nelson THE MIT PRESS 200 pp. \$32 (2010)

Biometric technologies — such as fingerprint sensors, retina scans and handwriting analysis — are increasingly used to identify individuals. Drawing on research with focus groups, political scientist Lisa Nelson explores public attitudes to surveillance. She describes how public users of these technologies are sensitive to issues of privacy, trust and confidence in the institutions that acquire it. The expansion of these identification methods by governments through history, she explains, has bred distrust in biometrics, and highlights the need to balance harm, prevention and liberty.

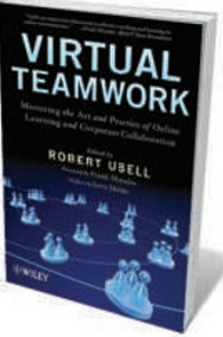

Virtual Teamwork: Mastering the Art and Practice of Online Learning and Corporate Collaboration

Edited by Robert Ubell WILEY 268 pp. $\$ 49.95$ (2010)

Scientists increasingly work and teach in collaborations that have remote members. This collection of expert perspectives, edited by enterprise-learning professor Robert Ubell, offers a practical guide to virtual teamwork. It explains how to communicate across borders of geography, culture and motivational style to manage productive exchanges between participants. The essays offer advice on running online class projects and detail the latest virtual team technology. 